\title{
ADOPTION OF TALENT MANAGEMENT PRACTICES FOR MANAGING DIVERSITY RELATED ISSUES IN SERVICE ORGANIZATIONS IN PUNE REGION
}

\section{DR. SUNETRA GAITONDE \& UPENDRA LELE}

IndSearch Institute of Management Studies \& Research, Pune

\begin{abstract}
People are the assets of any organization as the organizations are struggling to have the best and the brightest talent with them. Recent research and data have indicated that although employee diversity could create conflicts and thereby hampering organizational performance, diversity in business leadership and management teams also may lead to better business outcomes. It is important that in the event of co-existence of multiple diversities at the workplace, the underlying differences between them are leveraged for greater business benefits. Diversity at workplace leads to innovation, creative ideas and a positive impact on productivity. Companies should consider adopting or endorsing an official policy on these issues, and developing a strategy to implement the policy. Talent management today has become one of the common and important terms in the Human Resource Department. The objective of this research is to investigate different types of diversity issues that affect the productivity and organizational performance. The study indicates that talent management practices can help the organizations in addressing diversity issues. It is an exploratory study about talent management practices being followed by service organizations in Pune.
\end{abstract}

KEYWORDS: Talent Management Practices, Diversity, Pune

Received: Jan 03, 2021; Accepted: Jan 23, 2021; Published: Mar 17, 2021; Paper Id.: IJBMRFEB20211

\section{INTRODUCTION}

In the current scenario of the rapid changing economy, it is crucial to understand diversity and its impact on the success of the organization. Companies that are struggling to sustain in the global market take the initiative to promote diversity at workplace. To be a leader in the global market it is essential for organizations to leverage workforce diversity and work culture to meet the changing demographics of the customers. Nationality, age, race, gender and culture are some of the criteria for diversity definition.

Talent Management emerged in the 1990s and has been a significant term in organizations as skills, talent and employee motivation are the vital aspects for a successful business. It is essential for such successful organizations to have an efficient flow of diverse talent since the demand for talented leaders are increasing. New challenges are fostering due to globalization and demographic changes for firms that are competing for highly talented human capital resources and this war is aggressive among the Multinational Companies who are hungry for knowledge.

\section{LITERATURE REVIEW}

The available literature on cultural diversity, gender diversity, and generational diversity has been examined in order to understand the impact of diversity on organizational effectiveness and initiatives, if any, taken by organizations to address the issues arising from diversity in work force. 


\section{Cultural Diversity}

Practices of managing culturally diverse workforce in an International Business School in a Swedish University have been studied through empirical findings based on qualitative research. The study focuses on teachers' perception of issues arising out of cultural diversity and the policies adopted by the College-Management to address them. The results showed that even though the employees and management were aware of the cultural diversity issues, but the employees did not perceive that the management was effectively handling those issues. Since this was a qualitative research, quantified results of the employee dissatisfaction were not available. (Rashidat Abidemi Anjorin and Avni Jansari 2018)

A study carried out in 2012 has examined the challenges faced by global companies to cope with multicultural diversity (Quignon Fabien, Vettori Francesco 2012). They have noted that talent management is a key success factor to address the issues arising from cultural diversity, however, according to the authors these issues have not been adequately addressed so far. Though their work is based on management of football games, they have argued that the concepts and strategies are applicable to general businesses as well. They further stated that in global companies there are challenges in integrating multicultural teams. The authors noted that a new of leadership style has emerged in football teams where the leader makes an effort to integrate with the team members and remove the cultural and hierarchical barriers by focusing more on the team player's views and perspectives rather than their languages and cultures.

\section{Gender Diversity}

Japanese researchers have observed positive and significant impact of CSR on work life balance practices related to gender diversity (Kato Takao and Kodama Naomi 2016). They used panel data analysis of CSR practices followed in 14092 companies in Japan. They have suggested that Japanese policy makers should consider CSR as one of the important means for advancement of women in labour market.

A research involving global firms has examined the influence of gender diversity on employee productivity (Stefen Turban et al 2019). According to the research based on 1069 leading firms across 35 countries and 24 industries, it was observed that gender diversity is having a positive impact on improving the market value and revenue.

One of most recent studies focuses on policies for addressing issues related to gender diversity. The author has suggested policies (talent management practices) like flexible work for both men and women and reducing gender pay inequality for addressing gender diversity (Gazala Azmat 2020).

\section{Generational Diversity}

A study carried out in 2011 focuses on the expectations and perceptions of three different generations of employees at the workplace. The author has observed that the behaviour, attitudes, and work values of three generations (baby boomers, Gen $\mathrm{X}$ and Gen Y) of employees may be influenced by social, economic, and cultural experiences. This causes perception gap between the generations, thereby causing conflicts among the employees. The author has attempted to measure this gap qualitatively. At the end the author has made some recommendations for the management to ensure that individuals from different generations should perceive others positively, to avoid any disharmony and for the betterment of the organization (Tay Angeline 2011).

In a case study conducted on 23 employees of a home building company in Houston, it was observed that in a multigenerational environment, the employees were not sensitive to each-others' thoughts, feelings, and work values 
between different generations. If communication between generations improved then it would lead to better understanding and fewer conflicts between them by (Dev Lauton and Carlos Tasso E. De Acquino 2016).

An exploratory research was carried out in India to study the effects of generational diversity in Indian work force involving 5 different generations (Veterans, Free Gens, Gen X, E Gens, and Gen Ys). The authors reported specific differences in attitudes, competencies, and values associated with different generations that result in conflicts. Each generation has a unique set of competencies that are useful to the organization, and the organization should take proactive measures to bridge the gap between generations in order to put an organization on a path of success that is powered by innovation and commitment (Dr. Saundarya Rajesh and Karthik Ekambaram 2014).

\section{Importance of this study}

The above literature indicates that diversity of different types is one of the important causes for conflicts between employees, which may in turn adversely affect productivity and organizational performance. It is therefore important for the organizations to adopt certain measures to reduce the impact of such issues. Adopting effective talent management practices therefore assumes considerable importance. The modern industrial development has seen considerable shift in the work force from traditional sectors like agriculture and manufacturing to service sector. This study, which has focused on the service sector assumes considerable significance. We have also seen that in most of the studies cited in the literature, there is no mention of any specific talent management practices that could help the organizations in addressing diversity issues. This study aims to bridge this knowledge gap.

\section{Research Methodology}

This study is an exploratory enquiry into the talent management practices followed by organizations from service sector located in and around Pune. A pilot study indicated that the organizations were faced with issues related to three types of diversity, namely, gender diversity, generation related diversity, and cultural diversity. A questionnaire was prepared and circulated to 244 companies in the service sector and their responses were obtained on the following aspects related to diversity.

It was observed that the following types of talent management practices were adopted by the service organizations in Pune region. Refer Table 1.

Table 1: Talent Management Practices followed by Service Organizations

\begin{tabular}{|c|l|}
\hline Sr. & \multicolumn{1}{|c|}{ TM Practices followed for Managing Diversity } \\
\hline 1 & Ensure a mix of all ages in subgroups of department \\
\hline 2 & Ensure equal pay irrespective of gender \\
\hline 3 & Provide Security of female employees \\
\hline 4 & Paternity leaves for male employees \\
\hline 5 & Providing creche facility for employees' children \\
\hline 6 & Ensure that executive roles are available to Women \\
\hline 7 & Celebrating festivals of different cultures in the organizations on regular basis \\
\hline 8 & Provide opportunities to Baby Boomers to upgrade their knowledge on technology and latest trends \\
\hline 9 & Ensure a mix of all cultures in subgroups of department \\
\hline
\end{tabular}




\section{Research questions}

The study aims to address the following research questions in the context of employees' perception of effectiveness of talent management practices in managing diversity issues.

- Whether any talent management practices are adopted by the organization?

- What is the level or extent of adoption of talent management practices in the organization?

- How many organizations are adopting talent management practices?

- What is the effectiveness of talent management practices from employees' perspective?

\section{Data Analysis and Discussion of Results}

The responses received from employees working in 244 companies from the service sector in Pune are presented in the discussion below. Table 2 shows the demographic characteristics of the respondents.

Table 2: Company Size (Workforce)

\begin{tabular}{|l|c|}
\hline Workforce & No. of Companies \\
\hline Up to 50 & 70 \\
\hline 50 to 100 & 30 \\
\hline 100 to 500 & 55 \\
\hline 500 to 1000 & 19 \\
\hline Above 1000 & 70 \\
\hline & $\mathbf{2 4 4}$ \\
\hline
\end{tabular}

It may be seen from Table 2 above, that the data was obtained from small, medium, and large companies. Thus, it was a representative sample of the service industries in the region.

The respondents were asked whether any talent management practices existed in their organization. The result is presented in Table 3 below in the context of research question (A).

Table 3: Existence of Talent Management Practices in the Company

\begin{tabular}{|l|c|}
\hline $\begin{array}{c}\text { Whether TMP are } \\
\text { Present }\end{array}$ & No. of Companies \\
\hline Yes & 160 \\
\hline No & 84 \\
\hline Total & $\mathbf{2 4 4}$ \\
\hline
\end{tabular}

It was evident from the responses that 160 companies had Talent Management practices in place.

Next, the respondents were asked to gauge the level of adoption of talent management practices in their organization. The summary of their responses is presented in Table 4 below. 
Table 4: Level of Adoption of Talent Management Practices in the Company

\begin{tabular}{|l|c|c|}
\hline \multicolumn{1}{|c|}{ Level of Adoption } & No. of Companies & \% \\
\hline Adopted Partially & 89 & $36 \%$ \\
\hline Adopted Substantially & 57 & $23 \%$ \\
\hline Can't say & 37 & $15 \%$ \\
\hline Not at all Adopted & 16 & $7 \%$ \\
\hline Planning to Adopt & 11 & $5 \%$ \\
\hline No response & 34 & $14 \%$ \\
\hline Total & $\mathbf{2 4 4}$ & $\mathbf{1 0 0 \%}$ \\
\hline
\end{tabular}

It was observed that around $60 \%$ of the companies had either partially or fully adopted some talent management practices. This result is relevant from the point of view of research question (B).

The talent management initiatives related to diversity are listed below in Table 5. This result is in the context of research question $(\mathrm{C})$ :

Table 5: Talent Management Initiatives Taken by Organizations

\begin{tabular}{|c|l|c|c|l|}
\hline Sr. & TM initiatives for Managing Diversity & $\begin{array}{c}\text { Count of } \\
\text { Organizations }\end{array}$ & $\begin{array}{c}\text { \% of Total } \\
\text { Responses }\end{array}$ & \multicolumn{1}{|c|}{ Type } \\
\hline 1 & Ensure a mix of all ages in subgroups of department & 126 & $51.6 \%$ & Generation \\
\hline 2 & Ensure equal pay irrespective of gender & 139 & $57.0 \%$ & Gender \\
\hline 3 & Provide Security of female employees & 106 & $43.4 \%$ & Gender \\
\hline 4 & Paternity leaves for male employees & 63 & $25.8 \%$ & Gender \\
\hline 5 & Providing creche facility for employees' children & 32 & $13.1 \%$ & Gender \\
\hline 6 & Ensure that executive roles are available to Women & 91 & $37.3 \%$ & Gender \\
\hline 7 & $\begin{array}{l}\text { Celebrating festivals of different cultures in the } \\
\text { organizations on regular basis }\end{array}$ & 102 & $41.8 \%$ & Culture \\
\hline 8 & $\begin{array}{l}\text { Provide opportunities to Baby Boomers to upgrade their } \\
\text { knowledge on technology and latest trends }\end{array}$ & 30 & $12.3 \%$ & Generation \\
\hline 9 & Ensure a mix of all cultures in subgroups of department & 110 & $45.1 \%$ & Culture \\
\hline
\end{tabular}

The total count of initiatives is 799 . Considering 244 responses, the number of initiatives per organization comes to 3.27. It indicates a high level of awareness and focus of the companies towards addressing the diversity aspect.

The step in the analysis aims to answer research question (D). The respondents were asked how these talent management practices had an influence on organizational performance. Their response was sought on a 1 to 7 scale (1lowest, 7-highest) on the following specific aspects of organizational performance.

- Talent Management as practices can lead to effective enablement and productivity of resources through Training \& Development

- Talent Management as practices can reduce recruitment \& onboarding cycle time

- Talent Management as a practice can attract good candidates and talented professionals \& Help Recruitment \& Talent Acquisition

- Companies with Talent Management practices have better Workforce planning \& Attrition Management

- Talent Management practices positively affect organizational effectiveness 
The responses to the above aspects are summarized in Table 6 below.

Table 6: Effectiveness of Talent Management Practices in Improving Organizational Performance

\begin{tabular}{|l|c|c|}
\hline \multicolumn{1}{|c|}{$\begin{array}{c}\text { Impact of Talent Management Practice on } \\
\text { Organizational Performance }\end{array}$} & Mean & Standard Deviation \\
\hline $\begin{array}{l}\text { Talent Management practices positively affect } \\
\text { organizational effectiveness }\end{array}$ & 5.52 & 1.69 \\
\hline $\begin{array}{l}\text { Companies with Talent Management practices have better } \\
\text { Workforce planning \& Attrition Management }\end{array}$ & 5.53 & 1.58 \\
\hline $\begin{array}{l}\text { Talent Management as a practice can attract good } \\
\text { candidates and talented professionals \& Help Recruitment } \\
\text { \& Talent Acquisition }\end{array}$ & 5.54 & 1.52 \\
\hline $\begin{array}{l}\text { Talent Management as practices can reduce recruitment \& } \\
\text { onboarding cycle time }\end{array}$ & 5.21 & 1.62 \\
\hline $\begin{array}{l}\text { Talent Management as practices can lead to effective } \\
\text { enablement and productivity of resources through } \\
\text { Training \& Development }\end{array}$ & 5.64 & 1.57 \\
\hline
\end{tabular}

The above results show that the talent management practices related to diversity have a significant positive impact on the organizational effectiveness and performance.

The above results are in line with the earlier studies. In addition, the effectiveness of the talent management practices in managing diversity issues as perceived by the employees also shows encouraging results.

\section{CONCLUSIONS}

As observed, the results revealed that the organizations are adopting significant number of talent management practices in service organizations in Pune. The employees also have acknowledged the talent management practices followed in the organizations and expressed their opinions of the usefulness of these talent management practices in improving organizational performance. This also indicates that talent management practices are not only useful in addressing issues relating to diversity but also help in tapping the diverse potential of employees. Conclusions regarding the impact of diversity issues on HR and talent management practices should be viewed cautiously. Thus, companies should work more on the talent management practices to ensure employee engagement, resolving conflicts and enhancing retention strategies regardless of diversity issues.

\section{REFERENCES}

1. Angeline, T. (2011). Managing generational diversity at the workplace: expectations and perceptions of different generations of employees. African Journal of Business Management, 5(2), 249-255.

2. ANJORIN, R., \& Jansari, A. (2018). Managing Cultural Diversity at Workplace.

3. Azmat, G., \& Boring, A. (2020). Gender Diversity in Firms. Oxford Review of Economic Policy, 36(4).

4. Kato, T., \& Kodama, N. (2016). Corporate social responsibility and gender diversity in the workplace: Evidence from Japan. Rieti.

5. Lawton, D. S., \& Carlos Tasso, E. D. A. (2016). Diversity in the workplace and the impact of work values on the effectiveness of multi-generational teams. I-Manager's Journal on Management, 10 (3), 20-28. 

Service Organizations in Pune Region

6. Quignon, F., \& Vettori, F. (2012). Talent Management in a Multicultural Environment: A new game for global companies through the football's example

7. Rajesh, S., \& Ekambaram, K. (2014). Generational Diversity in the Indian Workforce: An Exploratory Study. International Journal of Managerial Studies and Research (IJMSR), 2(7), 54-64.

8. .Turban, S., Wu, D., \& Zhang, L. (2019). When gender diversity makes firms more productive. Harvard Business Review, 11. 
